\title{
Development and validation of a lung transplant-specific disability questionnaire
}

\author{
Jonathan Paul Singer, ${ }^{1}$ Paul David Blanc, ${ }^{1,2,3}$ Y Monica Dean, ${ }^{1}$ Steven Hays, ${ }^{1}$ \\ Lorriana Leard, ${ }^{1}$ Jasleen Kukreja, ${ }^{4}$ Jeffrey Golden, ${ }^{1}$ Patricia P Katz ${ }^{5}$
}

- Additional material is published online only. To view please visit the journal online (http://dx.doi.org/10.1136/ thoraxjnl-2013-204557).

${ }^{1}$ Division of Pulmonary, Critical Care, Allergy, and Sleep Medicine, Department of Medicine, University of California, San Francisco, USA ${ }^{2}$ Cardiovascular Research Institute, University of California, San Francisco, USA ${ }^{3}$ Division of Occupational and Environmental Medicine Department of Medicine, University of California, San Francisco, USA

${ }^{4}$ Division of Cardiothoracic Surgery, Department of Surgery, University of California, San Francisco, USA ${ }^{5}$ Department of Medicine and Institute for Health Policy Studies, University of California, San Francisco, USA

\section{Correspondence to:} Dr Jonathan Singer, Division of Pulmonary, Critical Care, Allergy, and Sleep Medicine, Department of Medicine, University of California, San Francisco, 350 Parnassus Avenue, Suite 609, San Francisco, CA 94117 USA; jon.singer@ucsf.edu

Received 25 September 2013 Revised 25 November 2013 Accepted 27 November 2013 Published Online First 19 December 2013

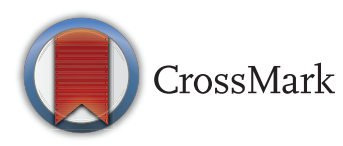

To cite: Singer JP, Blanc PD, Dean YM, et al. Thorax 2014;69:437-442.

\section{ABSTRACT}

Background Lung transplant (LT) aims to extend survival and improve patient-centred outcomes (PCOs) by reducing disability and improving health-related quality of life (HRQL). Few PCO instruments have been validated in LT populations. We aimed to develop and validate a shortened version of the valued life activities (VLA) disability scale specific to LT.

Methods We used data from 140 subjects participating in an ongoing cohort study of LT. Subjects completed a survey battery, including VLA items, and physical assessments before LT. To develop a shortened LT-specific VLA (LT-VLA), we iteratively deleted items from a longer 32-item VLA battery, retaining the instrument's conceptual framework, scoring and performance characteristics. We evaluated LT-VLA validity by testing correlations with a HRQL measure (Short Form-12 Physical Function (SF-12 PF) subscale), forced vital capacity \% (FVC\%) predicted and 6 minute walk distance (6MWD). Responsiveness was evaluated in 84 subjects who completed assessments before and after LT. Results The 15-item LT-VLA scoring closely matched the longer VLA (correlations $\geq 0.96$ ) and had excellent internal consistency (Cronbach's $\alpha$ 0.92). The LT-VLA required only 3 min or less to administer. The LT-VLA, measured as mean difficulty in performing each of the 15 activities queried, correlated with $\mathrm{FVC} \%$ predicted $(\mathrm{r}=-0.30), 6 \mathrm{MWD}$ $(r=-0.38)$ and SF-12 PF ( $r=-0.47)$ (all $p<0.01)$. The LTVLA mean difficulty was responsive to change from before to after LT (63\% improvement; effect size $=1.60$ ).

Conclusions The LT-VLA is a short, easy to administer, valid and responsive disease-specific PCO instrument that may be useful in clinical and research applications for lung transplantation.

\section{INTRODUCTION}

Improving patient-centred outcomes (PCOs), embodied by reduced disability and improved health-related quality of life (HRQL), is a prime clinical goal of lung transplantation (LT). ${ }^{1}$ Consistent with this priority, calls to incorporate PCOs into transplant decision-making are increasing. $^{2-4}$ To date, however, the tools to measure PCOs in LT have not been refined commensurate with the growing importance placed on such endpoints. Specifically, the performance characteristics and validity of most PCO instruments have not been established in LT populations, even though this is a prerequisite for reliable use. ${ }^{5}$ The profound disabilities experienced by LT candidates transcend the narrow constructs of difficulties in 'activities of daily living' (ADLs) or impediments to paid

\section{Key messages}

What is the key question?

- To develop a patient-centred disability measure for use in lung transplantation

What is the bottom line?

- We developed and validated a short, responsive disability measure that encompasses daily activities important to lung transplant patients.

\section{Why read on?}

- While improving patient-centred outcomes is a core clinical goal of lung transplantation, instruments validated in this population are scant; herein, we outline the development of a novel, lung transplant-specific measure of disability using established methods for instrument development.

employment. In actuality, persons undergoing LT face disabilities that encompass activities spanning the full spectrum of function that many believe give life meaning. Examples include spending time with friends and family, other forms of social engagement and travelling. Persons suffering from advanced lung disease identify a return to 'normal life' as a primary motivation for undertaking transplant.

Thus, the available disability data, restricted to ADLs and employment, ${ }^{6}{ }^{7}$ have limited relevance to the full spectrum of disability across daily life. Clinically, measuring disability in this way falls short of providing an adequate answer to the oft-asked question: "What will I be able to do after transplant?" In the research context, ADL-defined disability demonstrates a floor effect, in which all patients score rather well and do not appear to change over time. This floor effect may limit instrument sensitivity to measuring the effect of interventions, even LT.

Quantifying disability in terms of valued life activities (VLA) is an approach to PCO measurement that assesses a wide spectrum of daily life activities. The VLA scale, originally developed in rheumatoid arthritis (RA), ${ }^{8}$ was later adapted to disease-specific measures in asthma and chronic obstructive pulmonary disease (COPD). ${ }^{9}$ At 32 items, however, the complete VLA scale takes 10-12 min to administer. This time may present a 
substantial burden to respondents and a barrier to inclusion in multi-instrument survey batteries. We aimed to shorten the VLA scale and validate it for use specifically in LT. Our goal was to develop an instrument whose performance characteristics would make it useful for research and also amenable to potential clinical applications.

\section{METHODS}

\section{Data source}

We performed this study among participants in the University of California, San Francisco (UCSF) 'Breathe Again' study, an ongoing prospective cohort study of adults undergoing LT. Initiated in 2010, Breathe Again aims to study the impact of LT on HRQL and disability and to identify pulmonary and extrapulmonary determinants of HRQL and disability after LT. Briefly, subjects with end-stage lung disease are enrolled around the time of LT candidacy listing. At enrolment, baseline assessments include structured interviews to ascertain sociodemographics, VLA disability and HRQL using standard instruments. They also complete a research clinic visit for physical assessments, including the 6 minute walk distance (6MWD). While listed for LT, assessments are repeated every 3 months; data most proximal to the date of transplant are deemed the pretransplant 'baseline' for the analyses we report here. The same survey and physical assessments are administered at regular intervals after transplant. If subjects miss research visits due to illness or other reasons, we conduct home visits or in-hospital evaluations to minimise selection bias. The UCSF Committee on Human Research approved this study.

\section{Valued life activities disability scale}

The original VLA scale is a 32-item instrument that measures patient-reported ability to complete a broad spectrum of complex functioning in daily life. It operationalises a wellestablished conceptual model of disability that proposes a nonoverlapping hierarchy of disability across three activity domains: obligatory, required for survival and self-sufficiency (eg, (instrumental) ADLs); committed, associated with one's principal productive social roles (eg, working for pay or caring for family); and discretionary, such as socialising and engaging in leisure activities that provide relaxation and pleasure. ${ }^{10}$ Disease-specific variations of the battery have been validated in rheumatological and pulmonary conditions and are strongly associated with HRQL. 89 11-13

The VLA scale presents a list of activities and asks respondents to rate their difficulty in performing each one on a fourpoint scale $(0=$ no difficulty, $1=$ some difficulty, $2=$ a great deal of difficulty, $3=$ unable to perform). Additionally, respondents can indicate that any specific item is not relevant to them personally for reasons other than their health by selecting the response option 'does not apply'. By excluding items not deemed relevant by the respondent, VLA provides an individualised, clinically relevant measure of disability including only those activities that matter to the person completing the question battery.

Three summary scores can be calculated: mean difficulty (ie, sum of rated item scores/total items rated), proportion of activities affected (ie, number of items rated with a score $\geq 1 /$ total items rated) and proportion of activities that individuals are unable to perform (ie, number of items rated with a score $=3 /$ total items rated). Further, the same scoring algorithm can be applied to yield domain subscores for obligatory, committed and discretionary VLAs. For all scores, items rated as 'not relevant' are excluded from the denominator. The full VLA battery from which we derived the LT-specific measure and cohort responses to all its items is shown in online supplementary table S1.

\section{Other measures used to validate the lung transplant-specific VLA (LT-VLA) scale}

To assess the performance of the VLA scale and to identify which items best captured the PCOs of relevance to our LT population, we started with the conceptual model of disablement, which has been previously validated in COPD. ${ }^{10}{ }^{14}$ In addition to a hierarchy of activities, the model proposes that the pathway to disability begins with organ dysfunction due to disease, termed impairment. Impairment, in turn, leads to reductions in actions, termed functional limitations. Functional limitations are actions measurable in an easily quantifiable manner (eg, walking during a 6MWD). Functional limitations may then lead to disability, defined as difficulty performing activities in daily life (eg, walking to the grocery store). Although this model does not extend to HRQL, disability is clearly linked to poorer HRQL, as we have shown with the VLA approach. ${ }^{13} 1516$

Thus, we tested construct validity of the LT-VLA by assessing its relationship to measures of impairment, functioning and HRQL. We selected forced vital capacity (FVC) \% predicted as a measure of pulmonary impairment. We abstracted $\mathrm{FVC} \%$ predicted from medical records. We selected 6MWD, performed in either the UCSF Clinical Pulmonary Function Testing Laboratory or the Clinical and Translational Sciences Institute Exercise Laboratory, as our measure of functioning. Because the VLA measures disability across a range of physical activities, we selected the Medical Outcomes Survey Short Form-12 Physical Function (SF-12 PF) subscale score as our measure of HRQL. The SF-12 is a validated, reliable and responsive generic health status instrument adapted from the Short Form 36-Item Health Survey (SF-36). ${ }^{17} 18$

\section{LT-VLA item reduction and validation}

An initial LT-VLA version was modelled on a shortened VLA measure (S-VLA) developed for RA. ${ }^{19}$ For the S-VLA, item response theory analyses were used to eliminate items while preserving the range of activity 'difficulty' to ensure that a range of activities, from low-physical demand activities such as self-care to higher-demand activities such as physical recreation, was included. The S-VLA correlated strongly $(0.97)$ with the original version; internal consistency and validity estimates for the S-VLA were excellent and closely corresponded to the original. Thus, to create the LT-VLA we used the S-VLA as a starting point. As expected, there were substantial differences in item response characteristics obtained in the RA and LT populations, so we next followed an iterative process for shortening measurement scales recommended by Goetz and colleagues. ${ }^{20}$ During this process, we chose items to ensure we met four goals: (1) adequately represent all three conceptual subdomains (obligatory, committed and discretionary), (2) preserve the spectrum of activity difficulty and hierarchy of activities, (3) achieve scoring and scale performance characteristics in the LT-VLA that correspond closely to the original VLA measure and (4) validate important psychometric properties of the LT-VLA in a LT population.

Internal consistency was evaluated using Cronbach's $\alpha$. Content validity of the LT-VLA scale was maintained by including a spectrum of items from the obligatory, committed and discretionary subdomains. We examined response patterns to confirm consistent response spread and mean difficulty levels in summary and subscale scores. We tested construct validity by calculating correlations (Spearman) among LT-VLA scores and FVC\% predicted, 6MWD and the SF-12 PF subscale. 
Table 1 Cohort characteristics

\begin{tabular}{|c|c|}
\hline & Total sample $(n=140)$ \\
\hline Age, years & $58.8(48.4-64.1)$ \\
\hline Female & $50(70)$ \\
\hline \multicolumn{2}{|l|}{ Race/ethnicity } \\
\hline Caucasian, non-Hispanic & $76(106)$ \\
\hline African-American & $5(7)$ \\
\hline Asian & $6(9)$ \\
\hline Hispanic & $11(15)$ \\
\hline American Indian/Alaska Native & $1(2)$ \\
\hline Other & $1(1)$ \\
\hline \multicolumn{2}{|l|}{ Education } \\
\hline Less than high school & $6(8)$ \\
\hline High school graduate & $14(19)$ \\
\hline Some college, no degree & $27(38)$ \\
\hline Associate degree, trade or vocational school & $21(29)$ \\
\hline College degree & $17(23)$ \\
\hline Professional degree & $14(19)$ \\
\hline No answer & $2(3)$ \\
\hline \multicolumn{2}{|l|}{ LAS listing category for lung transplantation } \\
\hline Group A (COPD) & $23(32)$ \\
\hline Group B (pulmonary arterial hypertension) & $4(5)$ \\
\hline Group C (cystic fibrosis) & $10(14)$ \\
\hline Group D (pulmonary fibrosis) & $63(88)$ \\
\hline Forced vital capacity, \% predicted & $50(38-62)$ \\
\hline Six minute walk distance, metres & $290(171-396)$ \\
\hline
\end{tabular}

Consistent with other observations of poor correlations between lung function and other measures of disability and HRQL, ${ }^{21}$ we hypothesised a priori that LT-VLA would have the lowest correlation with $\mathrm{FVC} \%$ predicted and the highest correlation with the SF-12 PF subscale, which is the most closely related conceptually.

Responsiveness, or sensitivity to change, is important for a PCO measure if it is to be useful in longitudinal studies. ${ }^{22}$ To examine responsiveness, we evaluated LT-VLA scores in the subset of subjects who had completed baseline assessments and survived to complete reassessments 3 months after transplant at the time of analysis $(n=84)$. We calculated both the percent change and the effect size of that change. ${ }^{23}$ We also calculated Spearman correlations between changes in the LT-VLA scores and changes in FVC\% predicted, 6MWD and SF-12 PF.

\section{RESULTS}

\section{Characteristics of the sample}

During the study period, we performed baseline assessments on 140 cohort members (table 1). Participants were 50\% female and $76 \%$ Caucasian, with a mean age of 55 ( \pm 13 years). Approximately three-quarters had achieved at least some college education. Reflecting that UCSF is a referral centre for interstitial lung disease, $63 \%$ had pulmonary fibrosis.

\section{Original VLA item and scale evaluation}

Consistent with the domain, all obligatory items were rated (ie, considered important) by all subjects. Overall, 19 of the original 32 items were rated by $\geq 90 \%$ of subjects (see online supplementary table S1); only one item was rated by $<50 \%$ (item \#11, 'School/education'). With the exception of item \#6 ('Sleeping'), all response options were used for all items. Before transplant,
Table 2 Lung transplant Valued Life Activities (LT-VLA) scale items

\begin{tabular}{|c|c|}
\hline Domain & Item \\
\hline Obligatory & $\begin{array}{l}\text { Walking outside, just to get around places you need to go on a } \\
\text { regular basis (not including walking for exercise) } \\
\text { Taking care of basic needs, such as bathing, dressing or personal } \\
\text { hygiene } \\
\text { Walking or getting around inside the home } \\
\text { Getting around the community by car or public transportation }\end{array}$ \\
\hline Committed & $\begin{array}{l}\text { Working at a job for pay } \\
\text { Doing heavier housework, such as vacuuming, changing sheets or } \\
\text { cleaning floors } \\
\text { Doing light housework, such as dusting or laundry } \\
\text { Preparing meals and cooking }\end{array}$ \\
\hline Discretionary & $\begin{array}{l}\text { Participating in physical recreational activities such as walking for } \\
\text { exercise, jogging, swimming, dancing, playing golf or bowling } \\
\text { Travelling out of town } \\
\text { Going to social events, parties or celebrations } \\
\text { Participating in leisure activities outside the home, such as going } \\
\text { to movies, restaurants, playing cards or bingo, or club meetings } \\
\text { Visiting friends or family members in their homes } \\
\text { Having friends or family members in your home } \\
\text { Participating in leisure activities in your home, such as reading, } \\
\text { watching television or listening to music }\end{array}$ \\
\hline
\end{tabular}

mean item difficulty ratings ranged from a low of 0.28 (item \#32, 'Participating in leisure activities in your home') to a high of 2.66 (item \#17, 'Participating in vigorous physical recreational activities').

Characteristics of both the original VLA and LT-VLA are shown in table 2 . Of the 32 original items, 7 items measured the obligatory domain, 9 the committed and 16 the discretionary. Relative to other populations, our cohort reported severe disability. $^{9} 1124$ Mean difficulty was 1.42 ( 1 SD 0.58), mean proportion of activities affected was $75 \%( \pm 20)$ and mean

Table 3 LT-VLA and original VLA battery characteristics (baseline, $n=140$ )

\begin{tabular}{lll}
\hline & LT-VLA & VLA \\
\hline $\begin{array}{l}\text { Number of items, total } \\
\text { Number of items by domain }\end{array}$ & 15 & 32 \\
$\quad$ Obligatory & 4 & \\
Committed & 4 & 7 \\
Discretionary & 7 & 9 \\
Cronbach's $\alpha$ (total) & 0.92 & 16 \\
Mean ( \pm SD) difficulty & $1.44 \pm 0.61$ & 0.95 \\
Range, mean difficulty & $0.21-3.00$ & $1.42 \pm 0.58$ \\
Number (\%) of scores at floor & 0 & $0.14-2.91$ \\
Number (\%) of scores at ceiling & $1(0.7)$ & 0 \\
Correlation with long form & 0.98 & 0 \\
Median (IQR) \% activities affected & $80.0(71.4,92.9)$ & - \\
Range, \% activities affected & $7.1-100$ & $74.8(67.3,88.4)$ \\
Number (\%) of scores at floor & 0 & 0 \\
Number (\%) of scores at ceiling & $25(17.9 \%)$ & $16(11.4 \%)$ \\
Correlation with long form & 0.97 & - \\
Median (IQR) \% activities unable & $16.7(7.0,32.1)$ & $14.3(7.1,28.6)$ \\
Range, \% activities unable & $0-93.3$ & $0-93.8$ \\
Number (\%) of scores at floor & $19(13.6 \%)$ & $13(9.3 \%)$ \\
Number (\%) of scores at ceiling & 0 & 0 \\
Correlation with long form & 0.96 & - \\
\hline LT-VLA, lung transplant Valued Life Activities disability scale. &
\end{tabular}


Table 4 Spearmen correlations between three LT-VLA metrics and other measures (all baseline, $n=140$ )

\begin{tabular}{|c|c|c|c|}
\hline & $\begin{array}{l}\mathrm{FVC} \% \\
\text { predicted }\end{array}$ & 6MWD & $\begin{array}{l}\text { SF-12 Physical } \\
\text { Function }\end{array}$ \\
\hline LT-VLA mean difficulty & $-0.30 * *$ & $-0.38 * * *$ & $-0.47^{* * *}$ \\
\hline $\begin{array}{l}\text { LT-VLA \% activities } \\
\text { affected }\end{array}$ & $-0.24^{* *}$ & $-0.29 * *$ & $-0.51^{* \star *}$ \\
\hline $\begin{array}{l}\text { LT-VLA \% activities unable } \\
\text { to perform }\end{array}$ & $-0.23^{* *}$ & $-0.32^{* *}$ & $-0.35^{* * *}$ \\
\hline
\end{tabular}

proportion of activities respondents were unable to perform was $23 \%( \pm 21)$. There was no floor effect (ie, no score of 0 ) for mean difficulty or proportion of activities affected. There were, however, 13 individuals (9\%) who scored at the floor for proportion of activities completely unable to perform. We found no ceiling effects for mean difficulty or proportion of activities unable to perform; there were, however, 16 individuals (11\%) who achieved a ceiling score for proportion of activities affected (ie, scored 100\%, meaning that all were affected to some degree).

\section{Item reduction to create LT-VLA}

Through an iterative process, 17 items were eliminated. Details of this iterative process and performance characteristics are provided in the supplemental materials (see online supplementary figure S1, tables S2 and S3). The 15 retained items (table 2 and online supplementary table S4) demonstrated balance across subdomains, even distribution of subject-rated item difficulty, and close correspondence with the original (table 3). Item \#8, 'Working at a job for pay', was approached as a special case. While only $63 \%$ of respondents reported this item as important, the ability to return to employment is an important clinical outcome for those of working age. Further, age appeared to affect response patterns to this item; only $34 \%$ of respondents who were aged $\geq 65$ rated this item as important. Thus, based on its unique clinical relevance, we elected to retain this item in the LT-VLA. Cronbach's $\alpha$ for the LT-VLA was excellent (0.92), and its mean scores and score ranges very closely approximated those of the complete battery. Ceiling effects were slightly more frequent for the LT-VLA version. Correlations between the three

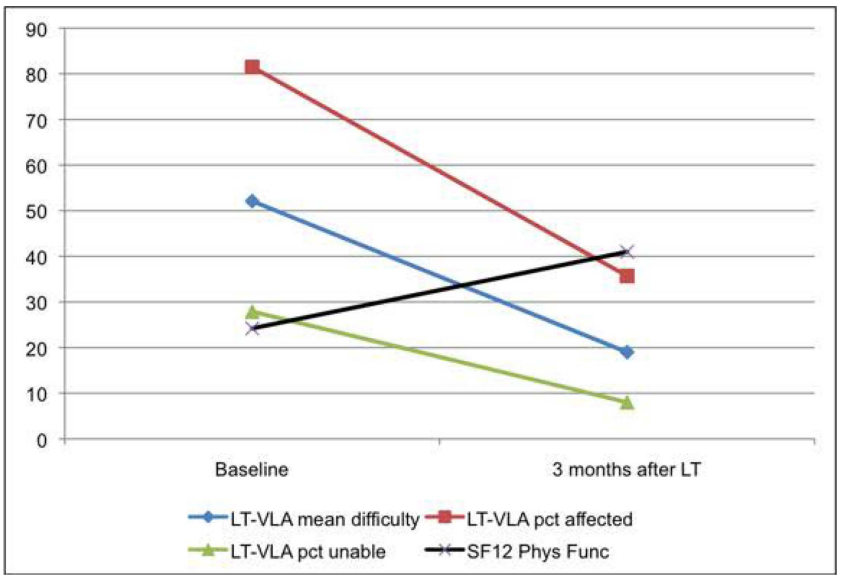

Figure 1 Responsiveness of lung transplant Valued Life Activities disability scale (LT-VLA) and Short Form-12 (SF-12) before and after lung transplant* . *To facilitate comparison with the SF-12, all LT-VLA scores transformed to 0-100 scale (transformation not necessary for standard scoring of LT-VLA). For all LT-VLA scoring approaches, lower scores reflect reduced disability, for SF-12 Physical Function scoring, higher scores reflect better health-related quality of life.

original and LT-VLA scoring approaches were excellent, ranging from 0.96 to 0.98 .

\section{LT-VLA cross-sectional validity}

The strength and direction of correlations between the LT-VLA and other measures were as hypothesised (table 4). Greater LT-VLA disability was significantly, but weakly, correlated with FVC\% predicted (range -0.30 to -0.23 , all $\mathrm{p}<0.01$ ). Slightly stronger correlations were identified between LT-VLA scores and 6MWD (range -0.38 to -0.29 , all $\mathrm{p}<0.01$ ). Finally, moderate correlations were found between LT-VLA scores and the SF-12 PF subscale (range -0.51 to -0.35 , all $\mathrm{p}<0.001$ ). Importantly, even the strongest correlations were only moderate, indicating that the LT-VLA is measuring similar but distinct theoretical constructs consistent with our conceptual model of disablement. All correlations were similar to the original VLA (see online supplementary table S5).

\section{LT-VLA responsiveness}

Depending on the scoring metric, LT-VLA scores improved between $56 \%$ and $71 \%$ from baseline to 3 months post-LT (table 5). Effect sizes of change were large (in a range

Table 5 LT- VLA responsiveness and change in other measures from before transplant to 3 months after transplant*

\begin{tabular}{|c|c|c|c|c|c|c|}
\hline & $\begin{array}{l}\text { Pretransplant } \\
\text { mean } \pm S D\end{array}$ & $\begin{array}{l}\text { Post-transplant } \\
\text { mean } \pm S D\end{array}$ & $\begin{array}{l}\text { Absolute change } \\
\text { mean } \pm S D\end{array}$ & t Statistict & Per cent change & Effect size $\ddagger$ \\
\hline LT-VLA mean difficulty & $1.56( \pm 0.62)$ & $0.57( \pm 0.49)$ & $-0.99 \pm 0.75$ & 11.84 & 63 & 1.60 \\
\hline LT-VLA \% activities affected & $81.5( \pm 16.6)$ & $35.7( \pm 27.7)$ & $-46.0 \pm 32.1$ & 12.83 & 56 & 2.76 \\
\hline LT-VLA \% activities unable to perform & $27.9( \pm 25.6)$ & $8.0( \pm 10.8)$ & $-19.9 \pm 28.7$ & 6.21 & 71 & 0.78 \\
\hline FVC $\%$ predicted & $48.2( \pm 17.0)$ & $71.6( \pm 17.1)$ & $23.2 \pm 19.8$ & 10.49 & 49 & 1.38 \\
\hline 6MWD, metres & $270( \pm 152)$ & $406( \pm 146)$ & $142 \pm 151$ & 6.84 & 50 & 0.89 \\
\hline SF-12 Physical Function & $24.2( \pm 5.6)$ & $41.0( \pm 12.8)$ & $17.1 \pm 13.1$ & 11.62 & 69 & 3.00 \\
\hline
\end{tabular}

*Includes only patients who have completed 3-month follow-up, $n=84$.

†Absolute value of the $t$-statistic from paired $t$ tests comparing pretransplant and post-transplant scores for each measure.

¥Effect size=(post-transplant mean - pretransplant mean)/baseline SD (23).

FVC\% predicted, forced vital capacity \% predicted; 6MWD, 6 minute walk distance; LT-VLA, lung transplant Valued Life Activities disability scale; SF-12 Physical Function, Medical

Outcomes Survey Short Form-12 Physical Function subscale. 
Table 6 Spearman correlation among changes in LT-VLA and changes in other measures from before transplant to 3 months after transplant $\dagger$

\begin{tabular}{|c|c|c|c|}
\hline & $\begin{array}{l}\text { FVC } \% \\
\text { predicted }\end{array}$ & 6MWD & $\begin{array}{l}\text { SF-12 Physical } \\
\text { Function }\end{array}$ \\
\hline Mean difficulty & -0.10 & $-0.30^{*}$ & $-0.33^{* *}$ \\
\hline$\%$ activities affected & -0.22 & $-0.44^{* *}$ & $-0.54^{* * *}$ \\
\hline$\%$ activities unable & 0.07 & -0.07 & -0.03 \\
\hline $\begin{array}{l}\text { SF-12 Physical } \\
\text { Function }\end{array}$ & -0.01 & $0.39 * *$ & - \\
\hline \multicolumn{4}{|c|}{$\begin{array}{l}{ }^{*} p<0.05,{ }^{* *} p<0.01,{ }^{* *} p<0.0001 . \\
\text { tIncludes only patients who completed 3-month follow-up, } n=84 . \\
\text { FVC\% predicted, forced vital capacity \% predicted; 6MWD, } 6 \text { minute walk distance; } \\
\text { LT-VLA, lung transplant Valued Life Activities disability scale; SF-12 Physical Function, } \\
\text { Medical Outcomes Survey Short Form-12 Physical Function subscale. }\end{array}$} \\
\hline
\end{tabular}

considered to be clinically meaningful $)^{25}: 1.62$ for mean difficulty, 2.53 for proportion affected and 0.85 for proportion unable. Figure 1 illustrates normalised changes in the LT-VLA scores relative to changes in the FVC\% predicted and the SF-12 PF subscale. The original and LT-VLA scales yielded equivalent measures of improvement (see online supplementary table S6).

Changes in mean LT-VLA difficulty and proportion of activities affected correlated in the expected directions with changes in the 6MWD and SF-12 PF (table 6). Changes in LT-VLA scores were not significantly correlated with changes in $\mathrm{FVC} \%$ predicted. Changes in the proportion of LT-VLAs unable to perform were not statistically correlated with changes in the other measures.

\section{DISCUSSION}

Our results indicate that the 15 -item LT-VLA disability measure we developed is valid, performs well, is easy to administer, captures what it intends to and is responsive to change. The LT-VLA addresses a pressing clinical, research and regulatory need for validated disease-specific instruments for PCOs in LT. ${ }^{1-5} 2627$ Moreover, the rigorous developmental process we used was informed by a validated conceptual model of disablement and by accepted standards for shortening established measurement scales. The LT-VLA has performance characteristics similar to the original battery but only requires less than $3 \mathrm{~min}$ to administer as opposed to 10-12 for the full VLA or, for comparison, 8-10 for the SF-36.

Beyond its psychometric properties, the LT-VLA provides data of direct clinical relevance. While improved lung function is important, patients considering LT regard as more fundamental how any improvement may impact their ability to return to living a 'normal life'. Aside from relatively crude registry-based reports of ADL disability, ${ }^{6}$ up until now we have lacked the tools with which to counsel patients from data-based evidence. Our new instrument could help change that. Key to that, the LT-VLA extends the conceptualisation of disability to beyond simply those ADLs necessary for survival and self-care. It measures a hierarchy of activities across the obligatory, committed and discretionary domains originally defined by Verbrugge. ${ }^{10} \mathrm{It}$ is this last domain, subsuming activities such as visiting others and travelling, that is typically absent from other measures. Consistent with their vital nature to happiness, disability in discretionary activities is more strongly linked with depression and life satisfaction than disability in obligatory and committed domains in other conditions. ${ }^{8} 28$ Notably, $\geq 84 \%$ of respondents in our cohort rated each discretionary activity in the LT-VLA as personally important.
In addition to more comprehensively measuring what is important to patients, by measuring disability across domains, the LT-VLA may identify disability at an early stage more amenable to intervention. In the early stages of chronic disease, patients make accommodations such as limiting participation in activities not necessary for survival or by taking more time to perform them. ${ }^{29-32}$ Our previous findings in other conditions show that disability in the proportion of discretionary activities affected will also be the earliest manifestation of the disablement process in $\mathrm{LT}^{24} 33$ The LT-VLA may also provide a novel and responsive PCO measure for research on physical functioning. Regulatory agencies ${ }^{34}$ and the newly established Patient Centered Outcomes Research Institute ${ }^{27}$ emphasise the inclusion of PCOs in interventional trials. As multicentre trials in LT grow, it is likely that PCO measures will be required. Selecting a PCO instrument that effectively measures health domains expected to be impacted by an intervention is a critically important decision. For example, the SF-36 is a frequently used multidimensional PCO measure of eight conceptual health domains. $^{35}$ Only two of the eight domains, however, address physical functioning. As a result, it may not be responsive or discriminative to interventions focused primarily on this health domain. Other PCO measures of functioning, like ADLs, may also not be sensitive measures of change in disability. ${ }^{6}$ Indeed, bronchiolitis obliterans syndrome (BOS) develops in $10 \%$ of patients by 1 year after transplant and $50 \%$ by 5 years. ${ }^{6}$ While BOS is known to negatively impact both functioning and $\mathrm{HRQL},{ }^{5}$ there is no observable difference in ADL disability in patients surviving 1 and 5 years after LT. $^{6}$ These data suggest that ADL-based disability analyses may substantially underestimate difficulties LT patients experience in daily life and fail to identify opportunities for future interventional studies.

Our study faces the limitation of modest cohort size drawn from a single centre. Nonetheless, this actually is one of the largest cohorts used to validate a PCO instrument in a LT population. Of note, too, our cohort had a greater proportion of subjects with pulmonary fibrosis than national averages. ${ }^{6}$ It is possible, therefore, that the final items in the LT-VLA might have been different had this study been performed at other transplant centres or with a different distribution of lung diseases, for example, more persons with cystic fibrosis. In part for that reason, we elected to retain the work-related item. As is true for all shortened survey instruments, reduced respondent burden may come at the expense of reduced item diversity or scale performance. This could theoretically limit the ability of the LT-VLA to discriminate among subjects at the most severe end of the disability spectrum. The improvements observed at 3 months, however, argue against a ceiling limiting the LT-VLA's ability to respond to change.

In summary, the LT-VLA is a short, valid and responsive PCO instrument for measuring disability in LT. Further, the LT-VLA extends the concept of disability to clinically relevant domains. Its ability to encompass a broad range of daily life activities important to LT recipients is particularly important in comprehensively measuring disability for both clinical and research applications.

Acknowledgements The authors wish to thank Joan Chen, research coordinator with the UCSF Lung Transplant Research Group, for her outstanding effort on this project. Study data were collected and managed using REDCap electronic data capture tools hosted at UCSF. ${ }^{36}$ REDCap (Research Electronic Data Capture) is a secure, web-based application designed to support data capture for research studies, providing (1) an intuitive interface for validated data entry, (2) audit trails for tracking data manipulation and export procedures, (3) automated export procedures for seamless data downloads to common statistical packages and (4) procedures for importing data from external sources. 
Contributors JPS and PPK conceived of and designed the study and wrote the manuscript. JPS, PPK and PDB analysed the data. JPS, SH, LL, JG and JK contributed field expertise. JPS and YMD were responsible for collection and quality assurance of the data. All authors interpreted the results, and were involved in iterative revisions of the manuscript and approved the final draft for publication. JPS is the guarantor of this paper.

Funding National Heart, Lung, and Blood Institute K23 HL 111115 and a Nina Ireland Program in Lung Disease award (JPS). A portion of this study was also supported by the National Center for Research Resources at the National Institutes of Health (UCSF-CTSI UL1 RR024131).

Competing interests None.

Ethics approval UC San Francisco Committee on Human Research.

Provenance and peer review Not commissioned; externally peer reviewed.

Data sharing statement Data from this ongoing prospective cohort study may be made available to interested researchers by contacting the corresponding author.

\section{REFERENCES}

1 Orens JB, Estenne M, Arcasoy $\mathrm{S}$, et al. International guidelines for the selection of lung transplant candidates: 2006 update-a consensus report from the Pulmonary Scientific Council of the International Society for Heart and Lung Transplantation. J Heart Lung Transplant 2006;25:745-55.

2 Abecassis M, Bridges ND, Clancy CJ, et al. Solid-organ transplantation in older adults: current status and future research. Am J Transplant 2012:12:2608-22.

3 Thabut G, Fournier M. Assessing survival benefits from lung transplantation. Rev Mal Respir 2011;28:e1-6.

4 Yusen RD. Technology and outcomes assessment in lung transplantation. Proc Am Thorac Soc 2009;6:128-36.

5 Singer JP, Chen J, Blanc PD, et al. A thematic analysis of quality of life in lung transplant: the existing evidence and implications for future directions. Am J Transplant 2013:13:839-50.

6 Christie JD, Edwards LB, Kucheryavaya AY, et al. The Registry of the Internationa Society for Heart and Lung Transplantation: 29th adult lung and heart-lung transplant report-2012. J Heart Lung Transplant 2012;31:1073-86.

7 Paris W, Diercks $M$, Bright J, et al. Return to work after lung transplantation. J Heart Lung Transplant 1998;17:430-6.

8 Katz PP, Yelin EH. Activity loss and the onset of depressive symptoms: do some activities matter more than others? Arthritis Rheum 2001:44:1194-202.

9 Katz PP, Gregorich S, Eisner M, et al. Disability in valued life activities among individuals with COPD and other respiratory conditions. J Cardiopulm Rehabil Prev 2011;30:126-36.

10 Verbrugge LM, Jette AM. The disablement process. Soc Sci Med 1994;38:1-14.

11 Katz P, Morris A, Gregorich S, et al. Valued life activity disability played a significant role in self-rated health among adults with chronic health conditions. J Clin Epidemiol 2009:62:158-66.

12 Katz $\mathrm{P}$, Morris A, Yelin E. Subclinical disability in valued life activities among individuals with rheumatoid arthritis. Arthrit Rheum-Arthr 2008:59:1416-23.

13 Katz PP, Yelin EH, Eisner MD, et al. Performance of valued life activities reflected asthma-specific quality of life more than general physical function. J Clin Epidemiol 2004:57:259-67.

14 Eisner MD, Iribarren C, Blanc PD, et al. Development of disability in chronic obstructive pulmonary disease: beyond lung function. Thorax 2011:66:108-14

15 Blanc PD, Singer JP, Omachi TA, et al. Lung function decline predicts disability in valued life activities, which in turn predicts impaired quality of life. Eur Respir $J$ 2011;38:752-35

16 Singer JP, Katz PP, Chen J, et al. Change in disability is a determinant of quality of life in persons undergoing lung transplant. J Heart Lung Transplant 2012;31(S):504
17 Stewart AL, Hays RD, Ware JE Jr. The MOS short-form general health survey. Reliability and validity in a patient population. Med Care 1988;26:724-35.

18 Ware J Jr, Kosinski M, Keller SD. A 12-Item Short-Form Health Survey: construction of scales and preliminary tests of reliability and validity. Med Care 1996;34:220-33

19 Katz PP, Radvanski DC, Allen D, et al. Development and validation of a short form of the valued life activities disability questionnaire for rheumatoid arthritis. Arthritis Care Res 2011:63:1664-71.

20 Goetz C, Coste J, Lemetayer F, et al. Item reduction based on rigorous methodological guidelines is necessary to maintain validity when shortening composite measurement scales. J Clin Epidemiol 2013;66:710-8.

21 van Schayck CP, Rutten-van Molken MP, van Doorslaer EK, et al. Two-year bronchodilator treatment in patients with mild airflow obstruction. Contradictory effects on lung function and quality of life. Chest 1992;102:1384-91.

22 Singer JP, Yusen RD. Defining patient-reported outcomes in chronic obstructive pulmonary disease: the patient-centered experience. Med Clin North Am 2012:96:767-87.

23 Norman GR, Wyrwich KW, Patrick DL. The mathematical relationship among different forms of responsiveness coefficients. Qual Life Res 2007 $16: 815-22$

24 Katz PP, Morris A, Yelin EH. Prevalence and predictors of disability in valued life activities among individuals with rheumatoid arthritis. Ann Rheum Dis 2006:65:763-9.

25 Cohen J. Statistical power analysis for the behavioral sciences. New York: Academic Press, 1977.

26 Yusen RD. Lung transplantation outcomes: the importance and inadequacies of assessing survival. Am J Transplant 2009;9:1493-4.

27 Selby JV, Beal AC, Frank L. The Patient-Centered Outcomes Research Institute (PCORI) national priorities for research and initial research agenda. JAMA 2012:307:1583-4.

28 Katz PP, Gregorich S, Eisner M, et al. Disability in valued life activities among individuals with COPD and other respiratory conditions. J Cardiopulm Rehabil 2010;30:126-36.

29 Fried LP, Bandeen-Roche K, Williamson JD, et al. Functional decline in older adults: expanding methods of ascertainment. J Gerontol A Biol Sci Med Sci 1996;51: M206-14.

30 Fried LP, Bandeen-Roche K, Chaves PH, et al. Preclinical mobility disability predicts incident mobility disability in older women. J Gerontol A Biol Sci Med Sci 2000;55: M43-52.

31 Gignac MA, Cott C, Badley EM. Adaptation to chronic illness and disability and its relationship to perceptions of independence and dependence. J Gerontol B Psychol Sci Soc Sci 2000;55:P362-72.

32 Wolinsky FD, Miller DK, Andresen EM, et al. Further evidence for the importance of subclinical functional limitation and subclinical disability assessment in gerontology and geriatrics. J Gerontol B Psychol Sci Soc Sci 2005:60:S146-51.

33 Singer JP, Katz PP, Iribarren $C$, et al. Both pulmonary and extra-pulmonary factors predict the development of disability in chronic obstructive pulmonary disease. Respiration 2013;85:375-83.

34 Guidance for industry: patient-reported outcome measures: use in medical product development to support labeling claims: draft guidance. Health Qual Life Outcomes 2006; $4: 79$.

35 Ware JE Jr, Snow KK, Kosinski M, et al. SF-36 Health survey: manual and interpretation guide. Boston, MA: The Health Institute, New England Medical Center, 1993.

36 Harris PA, Taylor R, Thielke R, et al. Research electronic data capture (REDCap) — A metadata-driven methodology and workflow process for providing translational research informatics support. J Biomed Inform 2009;42:377-81. 